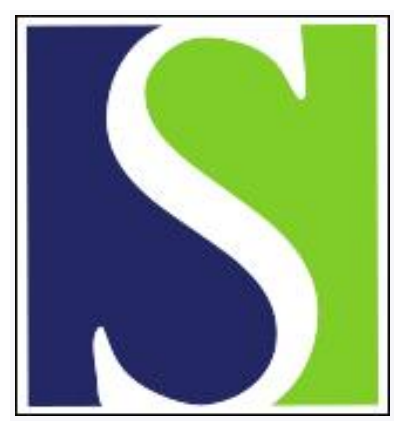

Scand J Work Environ Health 2005;31(3):165-167

https://doi.org/10.5271/sjweh.865

Issue date: Jun 2005

Corporate interests as an obstacle to the primary prevention of cancer

by Hagmar L, editor

Affiliation: Department of Occupational and Environmental Medicine, Lund University Hospital, SE-22185 Lund, Sweden. lars.hagmar@med.lu.se

Key terms: cancer; corporate interest; editorial; primary prevention

This article in PubMed: www.ncbi.nlm.nih.gov/pubmed/15999567

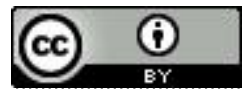




\section{Corporate interests as an obstacle to the primary prevention of cancer}

How is it possible that, still today, decades after we were presented with persuasive evidence that asbestos is carcinogenic, more than 2 million tons of asbestos is annually mined and used mainly in the developing countries and in Eastern Europe (1)? How can we explain that international organizations such as the World Health Organization (WHO) and the International Labour Organization (ILO) have been conspicuously weak and vague in their risk assessment efforts towards asbestos and not efficient in their risk management efforts?

This is one of the themes for the both passionate and somewhat disillusioned opinion expressed by Professor Lorenzo Tomatis, former director of the International Agency for Research on Cancer (IARC), in this issue of the Scandinavian Journal of Work Environment \& Health (2). Asbestos is perhaps the saddest example of an unacceptable time delay from sufficient knowledge until the implementation of a ban or sufficient restrictions in the field of occupational health. In western Europe alone, past asbestos exposure will cause at least half a million deaths during the next 35 years (1), and many of these deaths could have been avoided if preventive action had been taken earlier. But even worse, asbestos exposure is still going on in the parts of the world in which regulations are seldom enforced and voluntary standards are almost never implemented or monitored. Moreover, some rich industrialized countries take advantage of developing countries by exporting their old ships, stuffed with asbestos, to be demolished by ill-informed workers under poorly regulated conditions (3). This continuing exposure will result in an asbestos cancer epidemic for which corporate interests, some western governments (eg, Canada), and passive international organizations will share a heavy joint responsibility.

Unfortunately, asbestos is not the only example of an occupational carcinogen that has been regulated too late and too weakly. Aromatic amines, benzene, and bis-chloro methyl ether are other examples. Tobacco smoke, including environmental tobacco smoke, is also a carcinogen for which regulations have been late with respect to the overwhelming scientific evidence supporting its carcinogenicity.

Dr Tomatis remarks with bitter irony that: “. . . primary prevention [of cancer] should be given high priority, as one of its main characteristics is its universality, since it protects the rich and the poor, the strong and the weak indiscriminately [p 227]." Well, it seems obvious that enthusiasm has not been universal. And it would, of course, have been inexcusably naive to have believed anything else. The driving force behind corporate interests is to maximize profit for their shareholders, and some corporate interests have been very successful in defending the continuous production and marketing of products containing carcinogens. Industry representatives have also been successfully manipulating underfunded and meagerly staffed international organizations such as WHO and ILO (1), which, for risk assessment purposes, have used scientific experts that sometimes (but not always) have declared their association with the industry.

One of the main strategies for scientists associated with corporate interests has, according to Professor Tomatis, been "To claim that the evidence of carcinogenicity obtained with the use of laboratory animals exposed to high doses for a long time was unfit to predict similar effects on humans at lower levels of exposure made it easier to ignore or deny the fact that the carcinogenic effect observed for workers exposed to high concentrations would predict an analogous effect on the general population, which is exposed to much lower levels [p 228]." A recent example of such a dismissal of general principles otherwise commonly accepted in toxicologic risk assessment is some statements made in the aftermath of the disclosure that acrylamide is a cooking carcinogen (4). Available experimental data clearly indicate that acrylamide is carcinogenic in rats, producing tumors at multiple sites after exposure 
to low doses $(5,6)$. However, a well-known Swedish toxicologist claimed that humans may differ in sensitivity to acrylamide or may have quantitative or qualitative differences in metabolism and that this variation may limit the relevance of interspecies extrapolations [cited by Reynolds (7)]. Moreover, he claimed that a person would have to eat 75 kilograms of potato chips a day to get even one-tenth of the lowest observed genotoxic dose of acrylamide in rats [cited by Reynolds (7)]. I have seen no indications of any financial associations between this toxicologist and the food industry, but it is obvious that his arguments could be used by the food industry to challenge the health relevance of acrylamide with respect to different foodstuffs.

An open and matter-of-fact debate between independent scientists, scientists employed by government institutes or international organizations, and scientists associated with corporate interests is of great value in a careful risk assessment process. An example of such a constructive debate on the risk assessment in relation to vinyl chloride, between researchers associated with IARC and researchers associated with Dow Chemicals, is found in this issue of the Scandinavian Journal of Work Environment \& Health $(8,9)$. However, what can never be accepted is that formally independent researchers work undercover for corporate interests and do not openly report their conflicts of interest. Such fraudulent behavior must be regarded as deeply unethical. Several hired guns for, for example, the tobacco industry have been unmasked during recent years. The undercover work of researchers for the tobacco industry that was revealed during litigation in the United States led to agreements obliging the companies at issue to make a large number of confidential documents available on the Internet [Tobacco documents online (http://tobaccodocuments.org/)]. The University of Geneva has recently published a comprehensive and impressively frank report on an inquiry conducted by a fact-finding committee on the scientific misconduct alleged against a Swedish professor in environmental medicine, who was also an associate professor in the Medical Faculty of Geneva [University of Geneva. Suite et fin de l'Affaire Rylander-L'Université de Genève tire les leçons (press communiction). http://www.unige.ch/presse/ communique/?04-05/1029Rylander.html (in French)]. One of the conclusions of the report is worth citing: ". . . the Commission believes that concealing the true scope of the dependence on the tobacco industry and aligning his activities as a researcher and specialist in the areas of tobacco smoke with the strategic objectives of the industry constitutes an infringement of the scientific integrity that the general public and his peers were entitled to expect from a university researcher."

There are also recent concerns that not only have single researchers been undercover agents for the tobacco industry, but also the industry has been unduly influential with respect to the content of the scientific journal Indoor and Built Environment (10).

To conclude, corporate interests, and sometimes also political interests, form obstacles to the optimal primary prevention of cancer (and other diseases), but we will almost certainly have to live with this situation also in the future. So, what can we do? A positive trend is the increasing awareness of the problem among independent researchers and scientific journals. It is important to keep and strengthen independent evaluation efforts, such as the IARC Monograph Programme, which are not attached to corporate interests or to any political system. The recent interference of the White House, demanding changes to the scientific discussion of climate changes in a report from the Environmental Protection Agency in the United States, is ominous (11). We can only hope that this tendency by some countries to suppress unwelcome scientific knowledge will not continue, and, in any case, it should be strongly opposed in the future.

\section{References}

1. LaDou J. The asbestos cancer epidemics. Environ Health Perspect 2004;112:285-90.

2. Tomatis L. Primary prevention of cancer: science, sociocultural trends and economic pressures. Scand J Work Environ Health 2005;31(3):227-32. 
3. Harris LV, Kahwa IA. Asbestos: old foe in 21st century developing countries. Science Tot Environ 2003;307:1-9.

4. Rudén C. Acrylamide and cancer risk-expert risk assessments and the public debate. Food Chemical Toxicol 2004;42:335-49.

5. International Agency for Research on Cancer (IARC). Some industrial chemicals. Lyon: IARC; 1994. IARC monographs on the evaluation of carcinogenic risks to humans, vol 60.

6. World Health Organization (WHO). Health implications of acrylamide in food: joint FAO/WHO consultation, Geneva, Switzerland, 25-27 June 2002 [summary on the Internet]. Available at: http://www.who.int/foodsafety/publications/ chem/acrylamide_june2002/en/.

7. Reynolds T. Acrylamide and cancer: tunnel leak in Sweden prompted studies. J Natl Cancer Inst 2002;94:876-8.

8. Swaen GMH, Duijts SFA. Epidemiologic evidence for the carcinogenicity of vinyl chloride monomer [letter to the editor]. Scand J Work Environ Health 2005;31(3):233-5.

9. Boffetta P, Mundt KA, Dell LD. Response to Swaen \& Duijts on the epidemiologic evidence for the carcinogenicity of vinyl chloride monomer [letter to the editor]. Scand J Work Environ Health 2005;31(3):236.

10. Garne D, Watson M, Chapman S, Byrne F. Environmental tobacco smoke research published in the journal Indoor and Built Environment and associations with the tobacco industry. Lancet 2005;365:804-9.

11. Stokstad E. Environmental indicators: EPA report takes heat for climate change edits. Science 2003;300:2013.

Lars Hagmar

Department of Occupational and Environmental Medicine

Lund University Hospital

SE-22185 Lund, Sweden

lars.hagmar@med.lu.se 


\section{Scandinavian Journal of Work, Environment \& Health}

The Scandinavian Journal of Work, Environment \& Health is an international scientific periodical which began publication in 1975. The Journal appears 6 times a year, at the end of February, April, June, August, October, and December. In addition 1 to 3 self-financed supplements on specific topics are generally published annually.

The circulation of the Journal is worldwide. By the end of 2004, the total distribution was about 1100 copies to approximately 42 countries on 6 continents. Most of the subscriptions came from the United States (155), The Netherlands (87), Finland (73), Italy (57), Canada (49), Great Britain (48), Germany (43), Norway (42), Sweden (36), Spain (30), Australia (26), Denmark (26), France (24) and Japan (23).

The Journal is open to all authors without regard to nationality. In 2004, the number of manuscripts submitted for publication in a regular issue was 156. In volume 30, the first author of the 95 published articles (supplements included) was from Finland (20), Sweden (15), The Netherlands (12), the United States (11), Norway (7), France (7), Denmark (5), Canada (5), Germany (3), the United Kingdom (2), Lithuania (2), Estonia (1), Italy (1), Japan (1), New Zealand (1), Spain (1) and Switzerland (1).

The acceptance rate of the 156 articles submitted in 2004 was $23 \%$ by the end of March 2004; at that time the decision was still pending for 20 of the manuscripts.

In a peer-review process, 1 to 4 referees independently evaluate the scientific quality of the submitted manuscripts. The Journal uses a double-blind peerreview system.

The elapsed time from submission to publication for the articles published in 2004 averaged 9 months. A decision of acceptance of a manuscript was reached in 1 to 3 months (average 7 weeks).

The Journal is indexed or abstracted in Current Contents, the Science Citation Index, Biological Abstracts, Excerpta Medica, CISDOCE HSELINE, TZXLIRE, NIOSHTIC, etc.

For the latest year available, 2003, the impact factor of the Journal was 1.816 . 